\title{
TI.75.1
}

\section{Internet2 Security Activities: The Security Fruitcake}

- PDF: fruitcake-20060724.pdf

- Text: fruitcake-20060724.txt

\begin{tabular}{|c|c|}
\hline \multicolumn{2}{|c|}{ More Information } \\
\hline Repository ID & TI.75.1 \\
\hline Persistent URL & http://doi.org/10.26869/TI.75.1 \\
\hline Title & Internet2 Security Activities: The Security Fruitcake \\
\hline Authors & Ken Klingenstein, Chris Misra \\
\hline Sponsor & SALSA \\
\hline \multicolumn{2}{|l|}{ Review } \\
\hline Status & Legacy \\
\hline Publish Date & February 1, 2005 \\
\hline DOI & 10.26869/TI.75.1 \\
\hline \multicolumn{2}{|l|}{ Signature } \\
\hline Deprecated & No \\
\hline \multicolumn{2}{|l|}{ Future Review } \\
\hline \multicolumn{2}{|l|}{ Supersedes } \\
\hline Format & PDF, Text \\
\hline \multicolumn{2}{|l|}{ Related Docs } \\
\hline \multicolumn{2}{|l|}{ Development Location } \\
\hline \multicolumn{2}{|l|}{ IP Framework } \\
\hline Subject Tags & middlewarerescue \\
\hline Notes & \\
\hline
\end{tabular}

